\title{
Difficulty in taking medication and stroke among older adults with systemic arterial hypertension: the Fibra Study
}

\author{
Dificuldade em tomar medicamentos e acidente vascular encefálico \\ em idosos com hipertensão arterial sistêmica: Estudo Fibra
}

Juliana Lustosa Torres (https://orcid.org/0000-0002-3687-897X) ${ }^{1}$

Anita Liberalesso Neri (http://orcid.org/0000-0002-6833-7668) ${ }^{2}$

Eduardo Ferrioli (http://orcid.org/0000-0002-5028-2451) ${ }^{3}$

Roberto Alves Lourenço (http://orcid.org/0000-0003-0838-1285) ${ }^{4}$

Lygia Paccini Lustosa (https://orcid.org/0000-0002-0919-1320) ${ }^{5}$

${ }^{1}$ Departamento de Medicina Preventiva e Social, Faculdade de Medicina, Universidade Federal de Minas Gerais. Av. Prof. Alfredo Balena 190, sala 803 . 30130-100 Belo Horizonte MG Brasil.

jlt.fisioufmg@hotmail.com

${ }^{2}$ Faculdade de Ciências

Médicas, Universidade Estadual de Campinas. Campinas SP Brasil.

${ }^{3}$ Faculdade de Medicina, Universidade de São Paulo, Ribeirão Preto. Ribeirão Preto SP Brasil.

${ }^{4}$ Departamento de Medicina Interna, Faculdade de Ciências Médicas, Universidade do Estado do Rio de Janeiro. Rio de Janeiro RJ Brasil.

${ }^{5}$ Departamento de Fisioterapia, Escola de Educação Física, Fisioterapia e Terapia Ocupacional, Universidade Federal de

Minas. Belo Horizonte MG Brasil.

\begin{abstract}
This article aims to investigate whether difficulty in taking medication is associated with stroke among older adults with Systemic Arterial Hypertension (SAH) and to explore their association with living arrangements. Cross-sectional study was based on 3,502 older adults with SAH from the four universities pole of Frailty in Brazilian Older People (Fibra) Study, Brazil, including 14 municipalities of the five Brazilian regions. We used the medical diagnosis of stroke and difficulty in taking medications (self-reported difficulty and financial difficulty affording prescribed medications). Multivariate analysis was performed using logistic regression. Differently from women, older men with $S A H$, which report difficulty in taking medication (unintentional non-adherence), have higher odds of stroke. When stratified by living arrangements, those living with a partner have even higher odds of stroke compared to those without difficulty in taking medication and living alone. None association was found for difficulty affording prescribed medication for both men and women. Unintentional difficulty in taking medication plays a role in SAH treatment among men. Primary care strategies for controlling blood pressure should not be focus only on patients but targeting spouses as well.
\end{abstract}

Key words Activities of daily living, Aged, Hypertension, Medication adherence, Stroke
Resumo O objetivo deste artigo é investigar se a dificuldade em tomar medicamentos está associada ao acidente vascular encefálico (AVE) entre idosos com hipertensão arterial sistêmica (HAS) $e$ explorar esta associação com arranjos familiares. Estudo seccional baseado em 3.502 idosos com HAS dos quatro polos do Estudo Fibra, Brasil, incluindo 14 cidades das cinco regiões brasileiras. Foi usado o diagnóstico médico de AVE e a difculdade em tomar medicamentos (dificuldade autorrelatada e dificuldade financeira). Utilizou-se a regressão logística na análise multivariada. Diferentemente das mulheres, homens com HAS que relataram dificuldade em tomar medicamentos (não adesão não intencional) apresentam maior chance de ter AVE. Quando estratificado por arranjos familiares, homens que moravam com o cônjuge apresentaram chance ainda maior de ter $A V E$, quando comparados com aqueles sem difculdade em tomar medicamentos e que vivem sozinhos. Nenhuma associação foi encontrada para dificuldade financeira, tanto para mulheres quanto para homens. Dificuldades não intencionais em tomar medicamentos têm um papel importante no controle da HAS entre homens. Estratégias de controle da pressão arterial realizadas na atenção primária não devem focar apenas nos pacientes, mas nos cônjuges destes pacientes.

Palavras-chave Atividades cotidianas, Idoso, $\mathrm{Hi}$ pertensão, Adesão à medicação, Acidente vascular cerebral 


\section{Introduction}

Epidemiological and demographic transitions have been occurring particularly fast in Brazil ${ }^{1}$, urging the need for public policies to promote control and preventive care of chronic conditions. Systemic arterial hypertension (SAH) is a highly prevalent chronic condition among adults ${ }^{2,3}$ and older adults ${ }^{4}$ in Brazil. It is one of the main causes of premature morbimortality ${ }^{5,6}$. Yet, its treatment is one of the most common interventions in Primary Care. Although previous research shows decreasing prevalence trends ${ }^{2}$, its prevalence persists remarkably high among adults, over one-third ${ }^{3}$, and among older adults, nearly $50 \%{ }^{4}$.

Antihypertensive medications are one of the main therapies that started since the first stage of the disease ${ }^{7}$, along with non-pharmacological interventions. Improving blood pressure (BP) has been indicated as a health priority to avoid complications, such as stroke (and its sub derivations, such as mini-stroke), and decrease mortality ${ }^{6}$. Stroke is one of the most common causes of death worldwide that presents a major lifetime risk among adults with $\mathrm{SAH}^{8}$. Moreover, poor medication adherence among patients with SAH leads to a $27 \%$ higher risk of stroke?

Some of the greatest barriers for achieving BP control are the failure to prescribe antihypertensive medication ${ }^{10}$ and the lack of adherence to medication prescriptions (adequate and regular intake) $)^{10,11}$. Forty-four percent of both physicians and patients placed great importance on medication adherence ${ }^{12}$. The literature shows that one of the most common difficulties for not taking medication regularly is running out of medicine $^{11,13}$, most of the time due to poor financial condition ${ }^{14}$. However, it is important to add that the National Health System (Sistema Unico de Saúde, SUS) in Brazil provides freely or lower-priced antihypertensive medications when the patient has a prescription. Therefore, other factors might decrease pharmacological compliance. In Brazil, pharmacological compliance is around $59 \%$ among patients with $\mathrm{SAH}^{15}$, inversely associated with age, consulting with a physician less than once a year ${ }^{15}$, health beliefs ${ }^{13,16}$, side effects ${ }^{13}$, regular alcohol consumption, no previous myocardial infarction ${ }^{15}$, and polypharmacy ${ }^{14}$. Considering data from Barueri and Cuiabá, municipalities in Brazil, only $31.7 \%$ of older adults who report a diagnosis of SAH have their BP under control ${ }^{17}$.

Nevertheless, patients may present an unintentional non-adherence, described as a passive process whereby they fail to adhere to prescribing instructions through forgetfulness, carelessness, or circumstances out of their control ${ }^{18}$. Practical difficulties in taking medications are an activity measured commonly in epidemiological studies, classified as an instrumental activity of daily living (IADL). It is one example of unintentional non-adherence. According to the Brazilian National Health Survey ${ }^{19}, 31.8 \%$ of older Brazilian adults aged 65 and over report difficulty in taking medications by themselves. To the best of our knowledge, no previous study has investigated the impact of unintentional non-adherence drug treatment due to difficulty in taking medications on stroke among older adults with SAH. It is possible that not taking medications properly by themselves may negatively impact stroke when there is not an available person to help. Therefore, this study aims to investigate whether difficulty in taking medication is associated with stroke among older men and women with SAH and to explore their association with the living arrangements.

\section{Methods}

\section{Data source}

We conducted a cross-sectional analysis based on the Frailty in Brazilian Older People (Fibra) Study's participants. The Fibra Study is a multicenter network conducted in Brazilian municipalities of the five Brazilian regions, including Barueri (SP), Belém (PA), Belo Horizonte (MG), Campinas (SP), Cuiabá (MT), Ermelindo Matarazzo (SP), Fortaleza (CE), Ivotí (RS), Juiz de Fora (MG), Parnaíba (PI), Poços de Caldas (MG), Recife (PE), Ribeirão Preto (SP) e Santa Cruz (RN). The sample size in each municipality was calculated to achieve $50 \%$ of determined characteristics, according to the population total number of the municipality. It was a two-stage cluster sample design where: (1) the census tracts of the Instituto Brasileiro de Geografia e Estatística (IBGE - Brazilian Institute of Geography and Statistics) were randomly selected; (2) regarding the older adult population size in the selected census tracts, we set the minimum number of interviews in both census tracts and localities. All households in the selected census tracts were visited, and potential participants were invited to participate until we achieve the minimum number of interviews in that area.

Inclusion criteria of the Fibra Study were being at least 65 years old, being community-dwell- 
ing and having Mini-Mental State Examination $(\mathrm{MMSE})^{20}$ score higher than 17. According to Brucki et al. ${ }^{20}$, the median score among illiterate older Brazilian adults is 18 , considering a population-based sample of older adults aged 65 years and over. Participants were excluded whether they have been showing stroke sequel, Parkinson disease, using a wheelchair and being bedridden $^{21}$. Data was collected in $2008 / 2009$ by interviewers trained previously.

For this analysis purposes, only those who reported medical diagnoses of SAH were included. Due to the unavailability of objective measures of BP control, it was not measured directly. However, self-reported SAH has reasonable validity among older adults in Brazil, with an estimated sensitivity of $77 \%$ and specificity of $93 \%$ compared to clinical diagnosis and moderate concordance $(\text { Kappa }=0.59, \mathrm{p}<0.001)^{22}$.

Of the 6,762 older adults who took part in the Fibra Study, 3,622 had medical diagnosis of SAH. Among those, 3,502 (96.7\%) had full information on studying variables and were included. The flow of participants along with the reasons for exclusion is shown in Figure 1. Those excluded tended to be younger $(\mathrm{p}=0.01)$, and take a lower number of medication $(\mathrm{p}<0.001)$.

\section{Ethics approval and informed consent}

All participants signed the informed consent. The Fibra Study has been approved by the ethics committee of the four universities that supported the study (Universidade Federal de Minas Gerais, Universidade Estadual de Campinas, Universidade de São Paulo, and Universidade do Estado do Rio de Janeiro).

\section{Measures}

The study's outcome variable was stroke, measured by the history of medical diagnosis of stroke (at least one episode of stroke, diagnosed by a doctor, at any time in the past). The corresponding asked terms were "stroke", "cerebrovascular accident", "brain haemorrhage", and "cerebral ischemic". This is a validated measure and may be used in epidemiological studies, with an estimated sensitivity of $80 \%$ and specificity of $99 \%{ }^{23}$. Yet, the positive predictive value among individuals older than 60 years is greater than those younger than 60 years $(83 \%$ and $73 \%$, respectively $)^{23}$. The main determinants in this study were difficulty in taking medications. We included self-reported difficulty in taking medications, an IADL derived from the modified version of the Lawton IADL scale ${ }^{24}$, and difficulty affording prescribed medications. The difficulty affording prescribed medications was assessed by the question: "Do you skip any prescribed medication due to difficulty affording it?" (yes/no).

Other determinants of stroke were classified according to groups of social-demographic characteristics, health status and the number of medications. Social demographic characteristics included age, complete years of education, and living arrangements. Living arrangements were classified according to the family member living at the same house. It was divided into living alone, living with a partner and other arrangements (i.e. other relatives, such as grandchildren and siblings, and people out of the family, such as friends). Health status included the number of comorbidities, the medical diagnosis of depression, MMSE score, measured body mass index (BMI) and disability. The number of comorbidities was measured by self-reported medical diagnosis of chronic diseases, including diabetes, cancer, arthritis, lung disease, and osteoporosis. MMSE score was dichotomized into with and without cognitive impairment, considering the validated cut-off set for the Brazilian population across education categories (20 for illiterates and 24other education levels) ${ }^{25}$. Disability was assessed by self-reported limitations in IADL in six activities: preparing a meal, shopping for groceries, making telephone calls, doing work around the house, managing money, and taking public transport or $\mathrm{cab}^{26}$. We excluded from IADL the activity "taking medication" in order to avoid collinearity. Disability was defined as having any limitation in one or more activities.

\section{Statistical methods}

Descriptive analysis was based on Rao-Scott chi-square test whether the variables were categorical and based on t-test whether the variables were continuous. We implemented Logistic Regression to estimate the odds ratio (OR) and their 95\% confidence intervals to set the association between stroke and difficulty in taking medication. Multivariate analysis was performed adding groups of determinants as follows: (1) adjusting by social-demographic characteristics; (2) adjusting by health-related characteristics; (3) adjusting by the number of medications.

Additionally, we stratified the association between difficulty in taking medication and stroke by living arrangements to visualize how this rela- 


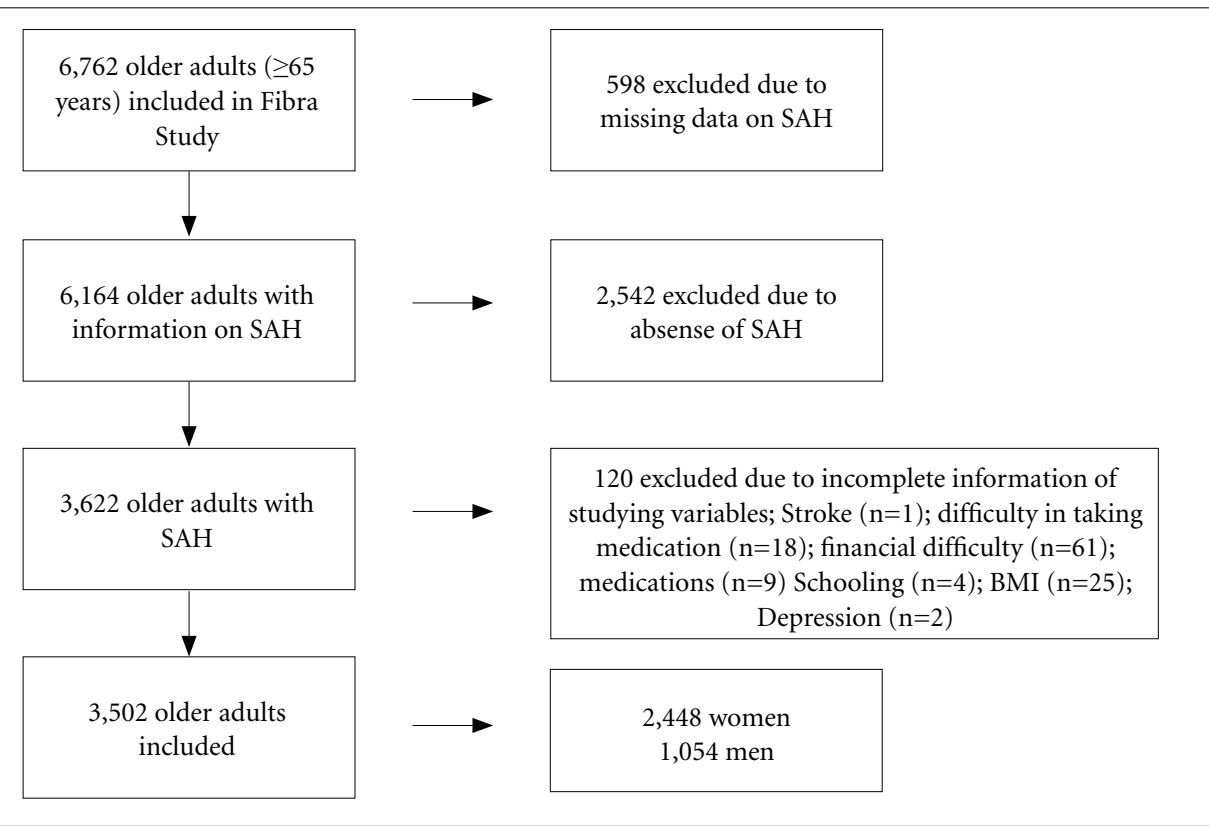

Figure 1. Flow diagram of sample selection. Systemic arterial hypertension (SAH) and difficulty in taking medication - Frailty in Brazilian Older People (Fibra) Study (2008-2009).

Source: Authors' elaboration.

tionship varies according to living arrangement categories. All analyses were performed using STATA 13.0 (Stata Corp LLP, College Station, TX), considering the sampling parameters (individual weight and household clustering of individuals), and conducted separately for men and women.

\section{Results}

The descriptive analysis by stroke is presented in Table 1. Most of the older adults were women $(70 \%)$, mean age 73.1 years $(\mathrm{SD}=6.1$ years). The prevalence of stroke was $8.6 \%$ (not including sampling parameters), self-reported by 302 participants. Difficulty in taking medication was reported by $8.5 \%$ of participants and difficulty affording prescribed medication by $24.7 \%$. Only age, living arrangement, BMI and cognitive impairment were not associated with stroke in the univariate analysis $(\mathrm{p}<0.05)$.

Table 2 shows the results of the multivariate analyses of the association between stroke and difficulty in taking medication for men and women. Among men, we observed a positive association between self-reported difficulty in taking medication and stroke $(\mathrm{OR}=1.96 ; 95 \%$
CI: $1.13,3.39)$ but not for difficulty affording prescribed medication $(\mathrm{OR}=0.86$; 95\% CI: 0.51 , 1.43). On the other hand, considering women, neither difficulty in taking medication nor difficulty affording prescribed medication was statistically significant (OR $=1.52$; 95\% CI: 0.95, 2.42 and $\mathrm{OR}=1.35 ; 95 \% \mathrm{CI}$ : 0.97, 1.88, respectively).

Additionally, we stratified difficulty in taking medication according to living arrangements and fitted another multivariate model to test possible modification. The results were shown in Table 3. We can see that men with difficulty in taking medication and living with a partner have higher odds (OR $=4.31 ; 95 \%$ CI: $1.43,12.96)$ of having stroke compared to those without difficulty in taking medication and living alone. This pattern was not observed among women $(\mathrm{OR}=1.13$; 95\% CI: 0.39, 3.25).

Based on these results, the predicted probability of having stroke among men and women was plotted in Graph 1.

\section{Discussion}

This study found that older men with SAH, which report difficulty in taking medication by themselves (unintentional non-adherence), have higher 
Table 1. Descriptive analysis of the participants with systemic arterial hypertension (SAH) according to stroke status - Frailty in Brazilian Older People (Fibra) Study (2008-2009).

\begin{tabular}{|c|c|c|c|c|}
\hline \multirow{2}{*}{ Variables } & \multirow[t]{2}{*}{ Total } & \multicolumn{2}{|c|}{ Stroke } & \multirow{2}{*}{ P value } \\
\hline & & No & Yes & \\
\hline Sex, $(\%)$ & & & & $<0.001$ \\
\hline Male & 30.0 & 29.2 & 39.4 & \\
\hline Female & 70.0 & 70.8 & 60.6 & \\
\hline Age, mean (SD) & $73.1(6.1)$ & $73.0(6.1)$ & $73.7(6.2)$ & 0.084 \\
\hline Years of education, mean (SD) & $4.3(4.2)$ & $4.4(4.2)$ & $3.9(3.8)$ & 0.039 \\
\hline Living arrangement (\%) & & & & 0.292 \\
\hline Living alone & 14.2 & 14.4 & 11.9 & \\
\hline Living with a partner & 32.1 & 31.8 & 35.4 & \\
\hline Other living arrangements & 53.7 & 53.8 & 52.6 & \\
\hline Body mass index, mean (SD) & $27.8(5.1)$ & $27.9(5.1)$ & $27.7(5.2)$ & 0.591 \\
\hline Number of medical diagnosis of chronic diseases, mean (SD) & $1.3(1.1)$ & $1.2(1.1)$ & $1.6(1.2)$ & $<0.001$ \\
\hline Medical diagnosis of depression (\%) & 20.5 & 19.9 & 27.2 & 0.003 \\
\hline Cognitive impairment ${ }^{\mathrm{b}}(\%)$ & 30.7 & 30.2 & 35.6 & 0.051 \\
\hline IADL Disabilityc $(\%)$ & 42.2 & 40.2 & 63.3 & $<0.001$ \\
\hline Number of medications, mean (SD) & $3.2(2.3)$ & $3.1(2.3)$ & $3.7(2.6)$ & $<0.001$ \\
\hline Difficulty in taking medications (\%) & 8.5 & 7.5 & 18.5 & $<0.001$ \\
\hline Difficulty affording prescribed medications (\%) & 24.7 & 24.1 & 30.5 & 0.015 \\
\hline Total & 3,502 & 3,200 & 302 & \\
\hline
\end{tabular}

Note: estimated percentages, considering the sampling parameters; SD: standart deviation; ${ }^{\mathrm{a}}$ including diabetes mellitus, angina or heart attack, cancer, arthritis, lung disease, osteoporosis; ${ }^{\mathrm{b}}$ measured by mini-mental state examination score, cutoff of 20 for illiterates and 24 other education levels; ' IADL: instrumental activities of daily living (preparing a meal, shopping for groceries, making telephone calls, doing work around the house, managing money and taking public transport or cab).

Source: Authors' elaboration.

Table 2. Multivariate logistic regression analyses of factors associated with stroke in 3,502 older adults with systemic arterial hypertension (SAH) by sex - Frailty in Brazilian Older People (Fibra) Study, Brazil (2008-2009).

\begin{tabular}{llrrr}
\hline \multirow{2}{*}{ Variables } & \multicolumn{2}{c}{ Men } & \multicolumn{2}{c}{ Women } \\
\cline { 2 - 5 } & OR & $\mathbf{9 5 \% ~ C I ~}$ & OR & \multicolumn{1}{c}{$\mathbf{9 5 \% ~ C I ~}$} \\
\hline Age & 1.00 & $0.96 ; 1.03$ & 0.99 & $0.97 ; 1.02$ \\
Years of education & 1.03 & $0.99 ; 1.08$ & 0.91 & $0.91 ; 0.99^{*}$ \\
Living arrangement (versus living alone) & & & & \\
$\quad$ Living with a partner & 2.06 & $0.90 ; 4.73$ & 0.82 & $0.49 ; 1.39$ \\
$\quad$ Other living arrangements & 1.20 & $0.51 ; 2.84$ & 1.05 & $0.68 ; 1.63$ \\
Body mass index & 0.93 & $0.89 ; 0.98^{*}$ & 1.01 & $0.98 ; 1.04$ \\
Number of medical diagnosis of chronic diseases & 1.11 & $0.90 ; 1.37$ & 1.32 & $1.15 ; 1.52^{\star *}$ \\
Medical diagnosis of depression & 1.17 & $0.68 ; 1.99$ & 1.34 & $0.95 ; 1.88$ \\
Cognitive impairment & 1.43 & $0.90 ; 2.26$ & 0.92 & $0.66 ; 1.29$ \\
IADL disability & 2.29 & $1.47 ; 3.55^{\star *}$ & 2.27 & $1.59 ; 3.22^{\star *}$ \\
Number of medications & 1.08 & $0.99 ; 1.16$ & 1.05 & $0.99 ; 1.12$ \\
Difficulty in taking medication & 1.96 & $1.13 ; 3.39^{*}$ & 1.52 & $0.95 ; 2.42$ \\
Difficulty affording prescribed medication & 0.86 & $0.51 ; 1.43$ & 1.35 & $0.97 ; 1.88$ \\
\hline
\end{tabular}

95\% CI: 95\% confidence intervals; OR: odds ratio, adjusted by all variables listed in the table; ${ }^{\text {a }}$ IADL: instrumental activities of daily living (preparing a meal, shopping for groceries, making telephone calls, doing work around the house, managing money, and taking public transport or $\mathrm{cab}){ }^{*} \mathrm{p}<0.05 ;{ }^{* *} \mathrm{p}<0.001$. 
Table 3. Stratified association of difficulty in taking medication and living arrangements with stroke among older men and women with systemic arterial hypertension - Frailty in Brazilian Older People (Fibra) Study (20082009).

\begin{tabular}{|c|c|c|c|c|c|c|}
\hline \multirow{3}{*}{ Variables } & \multicolumn{3}{|c|}{ Men } & \multicolumn{3}{|c|}{ Women } \\
\hline & \multirow[t]{2}{*}{ Prevalence } & \multicolumn{2}{|r|}{ Stroke } & \multirow{2}{*}{ Prevalence } & \multicolumn{2}{|c|}{ Stroke } \\
\hline & & OR $^{\mathbf{a}}$ & $95 \% \mathrm{CI}$ & & $\mathrm{OR}^{\mathrm{a}}$ & $95 \% \mathrm{CI}$ \\
\hline No difficulty and living alone & 7.1 & 1.00 & & 7.2 & 1.00 & \\
\hline No difficulty and living with a partner & 12.5 & 1.92 & $0.79 ; 4.66$ & 6.1 & 0.83 & $0.48 ; 1.44$ \\
\hline No difficulty and other living arrangements & 8.1 & 1.17 & $0.46 ; 2.98$ & 7.5 & 1.04 & $0.66 ; 1.65$ \\
\hline $\begin{array}{l}\text { Difficulty in taking medication and living } \\
\text { alone }\end{array}$ & 9.3 & 1.37 & $0.13 ; 14.19$ & 10.2 & 1.48 & $0.39 ; 5.64$ \\
\hline $\begin{array}{l}\text { Difficulty in taking medication and living } \\
\text { with a partner }\end{array}$ & 23.5 & 4.31 & $1.43 ; 12.96^{\star}$ & 8.0 & 1.13 & $0.39 ; 3.25$ \\
\hline $\begin{array}{l}\text { Difficulty in taking medication and other } \\
\text { living arrangements }\end{array}$ & 13.5 & 2.10 & $0.73 ; 6.07$ & 11.1 & 1.64 & $0.85 ; 3.16$ \\
\hline
\end{tabular}

Source: Authors' elaboration.
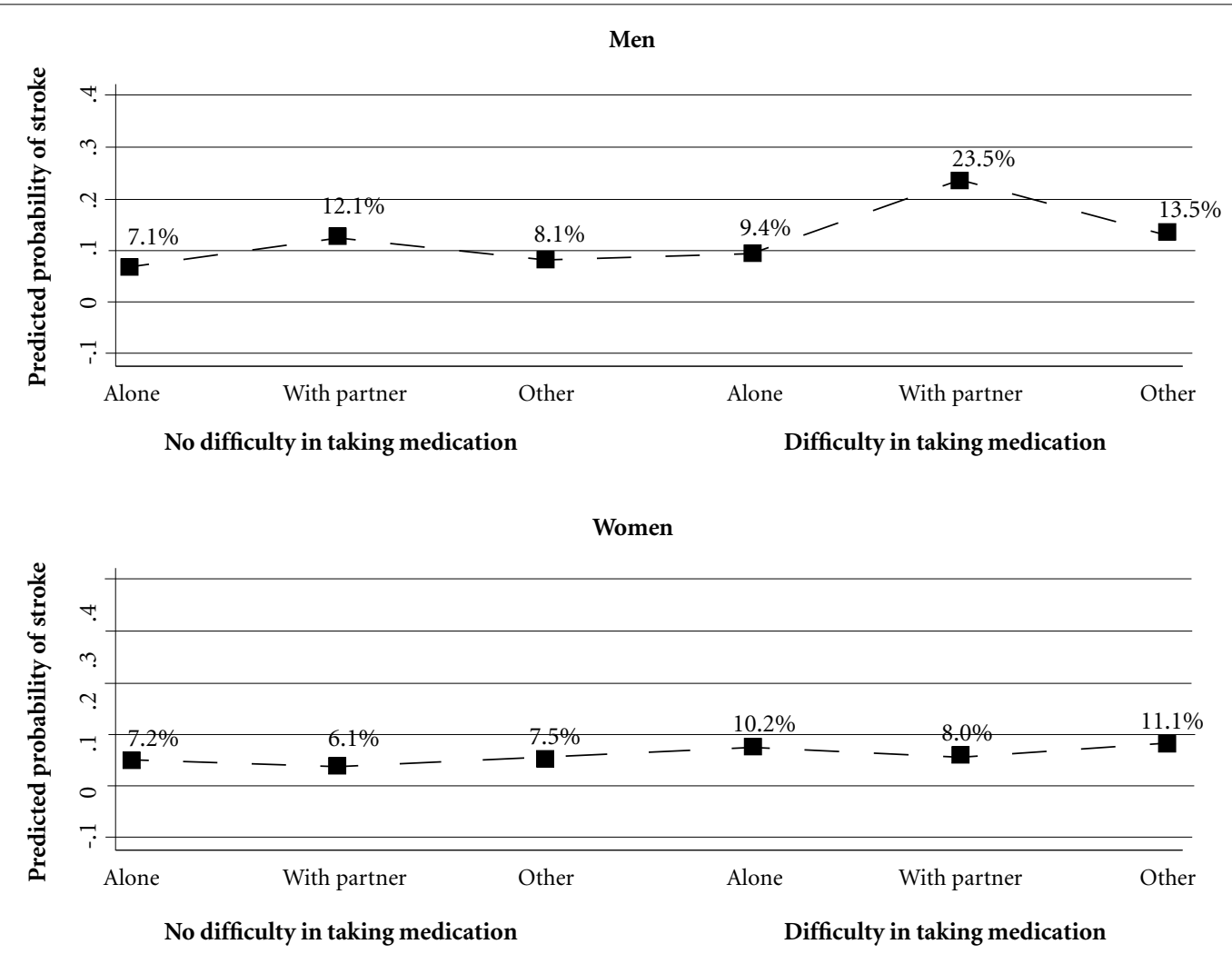

Graph 1. Predicted probability of having stroke among men and women according to difficulty in taking medication and living arrangement - Frailty in Brazilian Older People (Fibra) Study (2008-2009).

Source: Authors' elaboration. 
odds of stroke, but not women. Antihypertensive medications are one of the main therapies ${ }^{7}$ to control BP and avoid stroke. Surprisingly, when we stratified by living arrangements, those who have been living with a partner showed higher odds of stroke compared to those without difficulty in taking medication and living alone. We expected that living with a partner or other living arrangements might lead to adequate support availability and consequently higher treatment adherence. Indeed, our results should be interpreted carefully, considering our sample prevalence of difficulty in taking medication $(8.5 \%)$, quite low compared to Brazilian National Health Survey data $(31.8 \%)^{19}$. This variance could be attributable to our set cutoff of the MMSE at 17. Older adults with IADL disability have a lower MMSE score compared to those without (13.2 versus 16.9 among Brazilian men, respectively $)^{27}$. Therefore, we have been considering only people who are potentially independent but for some other reasons rather than cognitive impairment report difficulty in taking medication. This hypothesis was tested excluding those classified as having cognitive impairment according to the education level. After these exclusions, the association between wedded men who reported difficulty in taking medication and stroke remained significant $(\mathrm{OR}=5.44 ; 95 \% \mathrm{CI}$ : 1.42, 20.85) (data not shown).

Despite relatively high levels of access and treatment among older people with $\mathrm{SAH}^{3}$, including physician visits and medication supply, hypertension control was fairly low in Brazil' ${ }^{28}$. Brazil has instituted a government program that provides lower-priced medications, named "Popular Pharmacy Program" (Farmácia Popular do Brasil) since 2004²9. Recently, most Brazilians with Hypertension have full access to medication (97.9\%), most available for free with a prescription via SUS (56\%) or lower-priced in drugstores accredited $(16 \%)^{30}$. Thus, as showed in our results, difficulty affording prescribed medication in Brazil is not relevant for BP control and avoiding SAH complications. Data from Brazilian older adults ( $\geq 50$ years) under antihypertensive drug treatment has shown a BP under control prevalence of $51.1 \%{ }^{31}$, whereas considering only elderlies ( $\geq 65$ years) with hypertension, BP under control prevalence decreases to $31.7 \%{ }^{17}$. Some of the greatest barriers for achieving BP control are the lack of medication adherence ${ }^{10,11}$ (adequate and regular intake), due to both intentional and unintentional. Our findings support that unintentional non-adherence plays a role in stroke. For instance, a cohort study from Korea found that poor adherence (i.e. medication possession ratio less than $50 \%$ ) to antihypertensive drugs increased the risk of cerebrovascular disease by $27 \%$ compared with those that showed higher adherence? .

Although BP control is low in both $\operatorname{sex}^{28}$, and consequently higher risk of stroke, we found that difficulty in taking medication (unintentional non-adherence) is significant only among men. Unintentional non-adherence is a passive process whereby patients fail to adhere to prescribing medication through forgetfulness, carelessness, or circumstances out of their control, which forgetfulness is the most common ${ }^{18}$. This process is not random and reported to be associated with sex, in the sense that women have 9\% lower odds ${ }^{18}$. Accordingly, previous studies have found that men were twice more likely than women to underutilize healthcare services, such as a general medical consultation or BP screening ${ }^{32}$. Women have been more proactive in accessing and using health services, providing greater opportunities to early treatment and preventive health education activities for controlling it in primary care settings ${ }^{3}$, including lifestyle changes and medication intake. In our study, despite women have a statistically higher prevalence of SAH $(63.5 \%$ in women versus $54.9 \%$ in men), the prevalence of stroke was statistically high among men than women, $11.3 \%$ and $7.5 \%$, respectively, showing that men have more complications (data not shown). Part of these might be attributable to the greater proportion of women with SAH using medication when they are under a drug treatment $(95.2 \%)$ compared to men $(93.4 \%, \mathrm{p}=$ $0.026)^{30}$. On the other hand, lower education determines drug underutilization in both $\operatorname{sex}^{32}$. In the current study, this pattern was found among women, which showed decreasing odds of stroke for schooling ( $\mathrm{OR}=0.91$; $95 \% \mathrm{CI}$ : 0.91, 0.99).

Those data of poor hypertension control due to unintentional non-adherence reinforce the hypothesis that BP control is not an easy task. It often requires a life-long treatment that needs patients high compliant. Literature reports that routine use of home $\mathrm{BP}$ assessment improves antihypertensive medication adherence and BP control $^{10,33}$. Therefore, it is highly recommended along with other feedback techniques, such as pill boxes $^{33}$ and standardized measures ${ }^{34}$. Home visits are another way of reinforcing educational information about treatment for patients and caregivers and promote motivational interviewing ${ }^{33}$. Wide breadth of strategies, such as those made by nurse practitioners, is routinely recommended ${ }^{35}$. 
Yet, it is important to state that those strategies are more effective among women and high-income patients ${ }^{33}$.

Strikingly, when we stratified men with SAH by living arrangement, we found a higher odds of having stroke among those men who have difficulty in taking medication and living with a partner $(\mathrm{OR}=4.31 ; 95 \%$ CI: $1.43,12.96)$ compared to those without difficulty in taking medication and living alone. Therefore, those strategies should not be focus only on patients but targeting nonpaid caregivers as well. Some caregivers are themselves disabled, suffer from cognitive impairment or have lower education. In the case of a male stroke survivor who has a partner caregiver, the spouse may, for instance, withhold medication from the patient, give them a lower dose than recommended, forget to refill the prescription, or do not give the patient their medication at the right time ${ }^{36}$. Considering patients who have suffered a stroke, these behaviors may be strengthened by difficulty in taking medication arising from hemiplegia, visual field defects, unilateral neglect, and dysphagia ${ }^{36}$.

The current study has some positive and negative points. The primary positive point is the methodology using a community-based selected sample derived from fourteen municipalities from different regions of Brazil. This ensures its external validity to Brazilian community-dwelling older adults to guide policy-making. However, we should consider the cross-sectional design, which does not allow us to set a causal chain be- tween difficulty in taking medication and stroke. Thus, longitudinal study designs are needed to supply this gap. Furthermore, due to the unavailability of objective measures of BP control, it was not measured directly. Therefore, we cannot discard that informational bias (misclassification) may occur because of self-reportness, attenuating the estimated parameters. Although through the community-based sample we can estimate the impact of non-intentional medication adherence on stroke and reinforce primary care actions on medication adherence. Other pathways might explain the relationship between difficulty in taking medication and stroke rather than BP control, but our results are reasonable throughout literature. Yet, considering the large community-based population sample, important clinical measures of cardiac conditions that might influence in stroke were not available for adjustment. And we did not include lifestyle changes, such as salt intake or consumption of meat with visible fat, reported to be higher among male adults in Brazi ${ }^{37}$, which might influence pro and con BP control and its complications.

Considering men, unintentional difficulty in taking medication plays a role in SAH treatment to avoid adverse outcomes such as stroke. This pattern is especially important when the older adult is living with a partner, with increases, even more, the adverse outcomes. Therefore, primary care strategies for controlling blood pressure should not be focus only on patients, but targeting spouses as well. 


\section{Collaborators}

JL Torres contributed to idea and design; JL Torres, AL Neri, E Ferrioli and RA Lourenço contributed to acquisition of data, analysis and interpretation of findings; writing - original draft: JL Torres and LP Lustosa; writing - review and editing: JL Torres, AL Neri, E Ferrioli, RA Lourenço and LP Lustosa.

\section{Acknowledgements}

This study was supported by the Conselho Nacional de Desenvolvimento Científico e Tecnológico (CNPq), Coordenação de Aperfeiçoamento de Pessoal de Nível Superior (CAPES), and Fundação de Amparo à Pesquisa do Estado de Minas Gerais (FAPEMIG). The authors declare that they have no conflict of interest.

\section{References}

1. National Health Services. Global Health and Aging. NIH Publication No 117737, 2011. p. 273-277.

2. Picon RV, Fuchs FD, Moreira LB, Riegel G, Fuchs SC. Trends in prevalence of hypertension in Brazil: a systematic review with meta-analysis. PLoS One 2012; 7(10):e48255.

3. Macinko J, Leventhal DGP, Lima-Costa MF. Primary care and the hypertension care continuum in Brazil. J. Ambul Care Manage 2018; 41(1):34-46.

4. Picon RV, Fuchs FD, Moreira LB, Fuchs SC. Prevalence of hypertension among elderly persons in urban Brazil: a systematic review with meta-analysis. $A m$ J Hypertens 2013; 26(4):541-548.

5. Oliveira C, Marmot MG, Demakakos P, Mambrini JVM, Peixoto SV, Lima-Costa MF. Mortality risk attributable to smoking, hypertension and diabetes among English and Brazilian older adults (The ELSA and Bambui cohort ageing studies). Eur J Public Health 2016; 26(5):831-835.

6. Reis AF, Lima JC, Beccaria LM, Ribeiro RC, Ribeiro DF, Cesarino CB. Hypertension and diabetes-related morbidity and mortality trends in a municipality in the countryside of São Paulo. Rev Lat Am Enfermagem 2015;23(6):1157-1164.

7. Brasil. Ministério da Saúde (MS). Secretaria de Atenção à Saúde. Departamento de Atenção Básica. Hipertensão Arterial Sistêmica. Cadernos de Atenção Básica N. 15. Brasília: MS; 2006.

8. Turin TC, Okamura T, Afzal AR, Rumana N, Watanabe M, Higashiyama A, Nakao Y, Nakai M, Takegami M, Nishimura K, Kokubo Y, Okayama A, Miyamoto Y. Hypertension and lifetime risk of stroke. J Hypertens 2016; 34(1):116-122.

9. Lee HJ, Jang SI, Park EC. Effect of adherence to antihypertensive medication on stroke incidence in patients with hypertension: a population-based retrospective cohort study. BMJ Open 2017; 7(6):e014486.

10. Gee ME, Campbell NR, Gwadry-Sridhar F, Nolan RP, Kaczorowski J, Bienek A, Robitaille C, Joffres M, Dai S, Walker RL, Outcomes Research Task Force of the Canadian Hypertension Education Program. Antihypertensive medication use, adherence, stops, and starts in Canadians with hypertension. Can J Cardiol 2012; 28(3):383-389.

11. Martin MY, Kohler C, Kim YI, Kratt P, Schoenberger YM, Litaker MS, Prayor-Patterson HM, Clarke SJ, Andrews S, Pisu M. Taking less than prescribed: Medication nonadherence and provider-patient relationships in lower-income, rural minority adults with hypertension. J Clin Hypertens 2010; 12(9):706-713.

12. Liguori $Y$, Murase K, Hamamura M. Differences between patient and physician opinions on adherence to medication for hypertension and diabetes mellitus. Curr Med Res Opin 2016; 32(9):1539-1545.

13. Manfroi A, Oliveira FA. Difficulties in high blood pressure treatment compliance: considerations based on a qualitative study in a primary health care unit. Rev Bras Med Farm Com 2006; 2:165-176.

14. Guedes MV, Araújo TL, Lopes MVO, Silva LF, Freitas MC, Almeida PC. Barriers to hypertension treatment. Rev Bras Enferm 2011; 64(6):1038-1042. 
15. Girotto E, Andrade SM, Cabrera MAS, Matsuo T. Adherence to pharmacological and nonpharmacological treatment for arterial hypertension and associated factors in primary care. Cien Saude Colet 2013; 18(6):1763-1772.

16. Peres DS, Magna JM, Viana L. Arterial hypertension patients: attitudes, beliefs, perceptions, thoughts and practice. Rev Saude Publica 2003; 37(5):635-642.

17. Ricci NA, Pessoa GS, Ferriolli E, Dias RC, Perracini MR. Frailty and cardiovascular risk in communitydwelling elderly: a population-based study. Clin Interv Aging 2014; 9:1677-1685.

18. Gadkari AS, Mc Horney CA. Unintentional non-adherence to chronic prescription medications: how unintentional is it really? BMC Health Serv Res 2012; 12:98.

19. Brasil. Ministério da Saúde (MS). Pesquisa Nacional de Saúde. Brasília: IBGE; 2013.

20. Brucki SMD, Nitrini R, Caramelli P, Bertolucci PHF, Okamoto IH. Suggestions for utilization of the minimental state examination in Brazil. Arq Neuropsiquia$\operatorname{tr} 2003$; 61(3B):777-781.

21. Ferrucci L, Guralnik JM, Studenski S, Fried LP, Cutler GB Jr, Walston JD, Interventions on Frailty Working Group. Designing randomized, controlled trials aimed at preventing or delaying functional decline and disability in frail, older persons: a consensus report. $J$ Am Geriatr Soc 2004; 52(4):625-634.

22. Menezes TN, Oliveira ECT, Fischer MATS. Validity and concordance between self-reported and clinical diagnosis of hypertension among elderly residents in Northeastern Brazil. Am J Hypertens 2014; 27(2):215221.

23. Engstad T, Bonaa KH, Viitanen M. Validity of self-reported stroke: the Tromso Study. Stroke 2000; 31(7):1602-1607.

24. Almeida O. The mini-mental state examination and the diagnosis of dementia in Brazil. Arq Neuropsiquia$\operatorname{tr} 1998$; 56(3B):605-12.

25. Torres JL, Silva SLA, Lustosa LP. The role of education on the association between disability and depressive symptoms among community-dwelling older adults: evidence from Frailty in Brazilian Older People (Fibra) Study. Arch Gerontol Geriatrics 2019; 80:120-124.

26. Alexandre TS, Corona LP, Nunes DP, Santos JL, Duarte YA, Lebrão ML. Disability in instrumental activities of daily living among older adults: gender differences. Rev Saude Publica 2014; 48(3):379-389.

27. Pinho NA, Pierin AMG. Hypertension control in Brazilian publications. Arq Bras Cardiol 2013; 101(3):e65-e73.
28. Brasil. Decreto no 5.090, de 20 de maio de 2004. Regulamenta a lei $n^{\circ} 10.858$, de 13 de abril de 2004, e institui o programa "Farmácia Popular do Brasil", e dá outras providências. Diário Oficial da União 2004; 21 maio.

29. Mengue SS, Bertoldi AD, Ramos LR, Farias MR, Oliveira MA, Tavares NU, Arrais PS, Luiza VL, Pizzol TD. Access to and use of high blood pressure medications in Brazil. Rev Saude Publica 2016; 50(Suppl. 2):s8.

30. Firmo JOA, Mambrini JVM, Peixoto SV, Loyola Filho AI, Souza Junior PRB, Andrade FB, Lima-Costa MF. Adequate control of hypertension among older adults: ELSI-Brazil. Rev Saude Publica 2018; 52(Suppl. 2):s13.

31. Boccolini CS, Souza Junior PRB. Inequities in healthcare utilization: results of the Brazilian National Health Survey, 2013. Int J Equity Health 2016; 15(1):150.

32. Conn VS, Ruppar TM, Chase JAD, Enriquez M, Cooper PS. Interventions to improve medication adherence in hypertensive patients: systematic review and meta-analysis. Curr Hypertens Rep 2015; 17(12):94.

33. Carlson MC, Fried LP, Xue QL, Tekwe C, Brandt J. Validation of the hopkins medication schedule To identify difficulties in taking medications. J Gerontol A Biol Sci Med Sci 2005; 60(2):217-223.

34. Chang TE, Ritchey MD, Ayala C, Durthaler JM, Loustalot F. Use of strategies to improve antihypertensive medication adherence within United States outpatient health care practices, DocStyles2015-2016. J Clin Hypertens 2018; 20(2):225-232.

35. De Simoni A, Mant J, Sutton S. Adherence to medication in stroke survivors dependent on caregivers. $\mathrm{Br} \mathrm{J}$ Gen Pract 2015; 65(640):e789-e791.

36. Enes CC, Nucci LB. Gender and schooling inequalities in risk and protective factors for chronic diseases among Brazilian adults. J Public Health 2018; 40(3):e211-e218.

Article submitted 05/08/2019

Approved 29/10/2019

Final version submitted 31/10/2019

Chief editors: Romeu Gomes, Antônio Augusto Moura da Silva 